\title{
EARLY DETECTION AND SCREENING FOR DIABETIC RETINOPATHY
}

\author{
A. C. MACCUISH \\ Glasgow
}

The four cardinal principles of screening for human disease were defined concisely in a public health paper from the WHO in 1968.' Firstly, the condition sought should be an important health problem with a recognisable latent or pre-symptomatic stage. Secondly, a suitable and reliable screening test should be available, acceptable both to health care professionals and (more importantly) to the public. Thirdly, treatment for patients with recognised disease should be effective and agreed universally. Finally, the costs of early diagnosis and effective treatment should be balanced economically in relation to total expenditure on health care - including the consequences of leaving the disease untreated.

Today these seminal principles remain unchanged and diabetic retinopathy appears to be an ideal model for their application. Diabetes mellitus is common, affecting around $2 \%$ of the population in developed countries and (by WHO estimates) about $3 \%$ of the global population. Retinopathy is properly considered to be the commonest specific complication: indeed its development is almost inevitable if the patient lives long enough. In round figures, less than $5 \%$ of patients have retinopathy at diagnosis, this figure being comprised entirely of persons with type 2 (non-insulin-dependent) diabetes in whom a long period of occult carbohydrate intolerance is inferred. ${ }^{2}$ The prevalence rises to $40-50 \%$ after 10 years of overt diabetes, and after 20 years more than $90 \%$ of patients have some retinal abnormality. In many, the natural history is accelerated by concurrent hypertension or chronically poor glycaemic control. Retinopathy is detectable very easily by non-invasive techniques which are atraumatic for the patient, readily repeatable and simple for the clinician to master. The first recorded case of diabetic retinopathy was described in 1855 , a mere 5 years after the ophthalmoscope was invented. ${ }^{3}$ The treatment of sightthreatening retinopathy has been closely evaluated and refined over the past 20 years and is generally satisfactory. Photocoagulation with a monochromatic gas laser will

Correspondence to: Dr. A. C. MacCuish, Diabetes Centre, Royal Infirmary, Castle Street, Glasgow G4 OSF, UK. abolish new vessels in about $80 \%$ of patients with proliferative retinopathy; ${ }^{4}$ prolonged follow-up for more than 10 years indicates that the disease is stabilised or effectively cured in such patients; ${ }^{5}$ and at least in the developed countries, advanced techniques of vitreoretinal surgery can be highly effective for recurrent or late complications such as organised vitreous haemorrhage or traction retinal detachments. Laser therapy is less effective for maculopathy but still induces very effective visual salvage in about $60 \%$ of cases, ${ }^{6}$ and in both groups the results are further improved, perhaps by $10 \%$ respectively, if retinopathy is diagnosed and judiciously treated at its optimal early stage.

As to the economic implications of screening for retinopathy and thus preventing blindness, these have been examined much less closely than the natural history of the disease and its treatment. However, our own pilot study in 1983 in the West of Scotland estimated the cost of treating each patient at risk for blindness as $£ 387$ (US\$757, ECU546), set against average savings in social benefits (blind welfare services, unemployment and disablement benefits paid to blind persons) of $£ 3575$ (US\$7000, ECU5042) per annum. ${ }^{7}$ In 1989, a computer-simulated model based on the USA health care system yielded remarkably similar predictions: therapy costs of about $£ 558$ (US\$1000) per annum for vision salvage from proliferative retinopathy or maculopathy against savings in social benefits of $£ 3855$ (US\$7100) per annum for each blinded individual. ${ }^{8}$ What no cost-benefit analysis of screening, treatment or disability can tangibly measure is the misery and psychosocial dislocation endured by a person blinded by diabetes in adult life, but this aspect too has been studied and the problems are repellant. When we remember that a US Gallup poll indicated that $85 \%$ of the American public feared blindness above all else, ${ }^{9}$ it is not surprising that studies of diabetic patients confirm loss of sight to be their single most dreaded complication. ${ }^{10}$

Against this background - common disease, effective therapy, economic benefit, public alarm - it is highly discouraging to learn that diabetic retinopathy remains the 
single most common preventable cause of blindness in the working population (under age 65 years) of all European countries and the United States. ${ }^{11}$ It is more depressing that the statistic has remained unchanged for at least the past 20 years, i.e. the era in which effective therapy has been developed and widely used. We stand indicted for failure to deliver a supremely important aspect of health care to our patients and equally are culpable for failure to raise patient awareness of the visual risks which they incur if the eye is not examined. From best available data, it is probable that 1500-2000 diabetic patients per million population have high-risk retinopathy but that less than half are either aware of this or have sought ophthalmic advice in the preceding 2 years. ${ }^{11.12}$ In short, we can only do better and the St Vincent Declaration - convened by the WHO and IDF, and supported by more than 30 countries has declared a target of reducing new blindness due to diabetes by one third in Europe by $1995 .^{13}$ The aim seems modest in theory, most formidable in practice: the process starts with screening.

\section{THE SIGHT-THREATENING RETINOPATHIES}

Numerous elaborate classifications of diabetic retinopathy have been devised, the Airlie House nomenclature being most widely accepted and internationally used. Whilst an extended classification is both essential and invaluable for objective comparisons by experts in the field, the nonspecialist can adopt a much simpler classification with the assurance that the very large majority of at-risk patients have been safely identified. In essence, there are three varieties of sight-threatening retinopathy ${ }^{14}$ and all require prompt referral to an opthalmologist for assessment (Fig. 1):

(a) Maculopathy: the presence of hard exudates within one disc diameter of the macula, with or without concurrent macular oedema.

(b) Pre-proliferative retinopathy: the presence of cottonwool spots (micro-infarcts), venous irregularities (beading, reduplication, loops), multiple haemorrhages and intraretinal microvascular anomalies. These appearances may be present in varying combinations and are the prelude to:

(c) Proliferative retinopathy: the presence of new vessels on the disc or elsewhere in the retina.

This simple subdivision gives no detail of large circinate or plaque hard exudates, advanced diabetic eye disease, etc., but it is assumed that such gross lesions will invariably be referred, as should any patient in whom the observer cannot interpret the findings with confidence.

How commonly will these appearances be seen? In any large diabetic clinic with a spectrum of patient age and disease duration, about $30 \%$ of all patients will have some degree of visible retinopathy. ${ }^{15}$ In most the lesions will be of a benign or background nature (micro-aneurysms, scattered dot and blot haemorrhages, often near the posterior pole), but in approximately $10 \%$ ischaemic changes will be observed. More than one clinical variant of sightthreatening retinopathy may be present in a single eye, but in broad terms proliferative retinopathy is associated with younger, insulin-dependent patients and maculopathy with the older non-insulin-dependent diabetic. The latter form of diabetes is much more common; thus maculopathy is now the most frequent visual threat. A competent and experienced observer will identify the lesions with confidence, whether ophthalmoscopically or by examination of fundus photographs. The overall diabetic clinic prevalence figure of $30 \%$ for retinopathy gives a useful rule of thumb: if a retinal abnormality is not detected in every third patient, the screening technique is probably inadequate.

\section{SCREENING OPTIONS: GENERAL CONSIDERATIONS}

Three factors must be considered when choosing the screening option. Firstly, the most important attribute of an acceptable test for diabetic retinopathy is its sensitivity, which determines the number of false negatives. In a test which selects patients to be considered for laser therapy, the consequences of missing treatable disease are unacceptable when compared with the expense of unnecessary referrals. By contrast the test specificity, which determines the number of false positives, will affect primarily the cost-effectiveness of the programme.

Secondly, much has been made of the fact that hardly any of the numerous published studies of screening methods have measured comparative method efficiency against an absolute 'gold standard' of accurate detection. Two such standards are extant, i.e. fluorescein angiography and 7-field stereo fundus photography. However the paucity in their use is testimony to their disadvantages in terms of cost, time and (with fluorescein) occasional morbidity. The absence of a gold standard to document every small red spot in the fundus is largely irrelevant when comparing methodologies to identify much more gross evidence of disease, and for the latter purpose the best practical gold standard must be examination by a consultant ophthalmologist using, if necessary, not only a direct ophthalmoscope but also the indirect instrument, slit lamp biomicroscopy and other impedimenta of the specialist.

Finally, ostensibly attractive screening options which examine retinal function rather than structure can be dismissed firmly as quite impractical. The best known of such is assessment of colour vision, since diabetic dyschromatopsia is a common true diabetic complication. However, dyschromatopsia is exhibited by about $75 \%$ of all diabetic patients and is far too imprecise for satisfactory screening, being a frequent finding in patients without retinopathy and occasionally absent in patients with significant eye disease. ${ }^{16}$ The accurate assessment of colour vision is a complicated and lengthy business, whether using the 100-hue test or Lanthony's D15 desatured panel. Similar fatal objections apply to other tests of retinal physiology (quantitative field analysis, spatial contrast sensitivity, etc.) and none should be considered as alternatives to visualising the fundus oculi. 

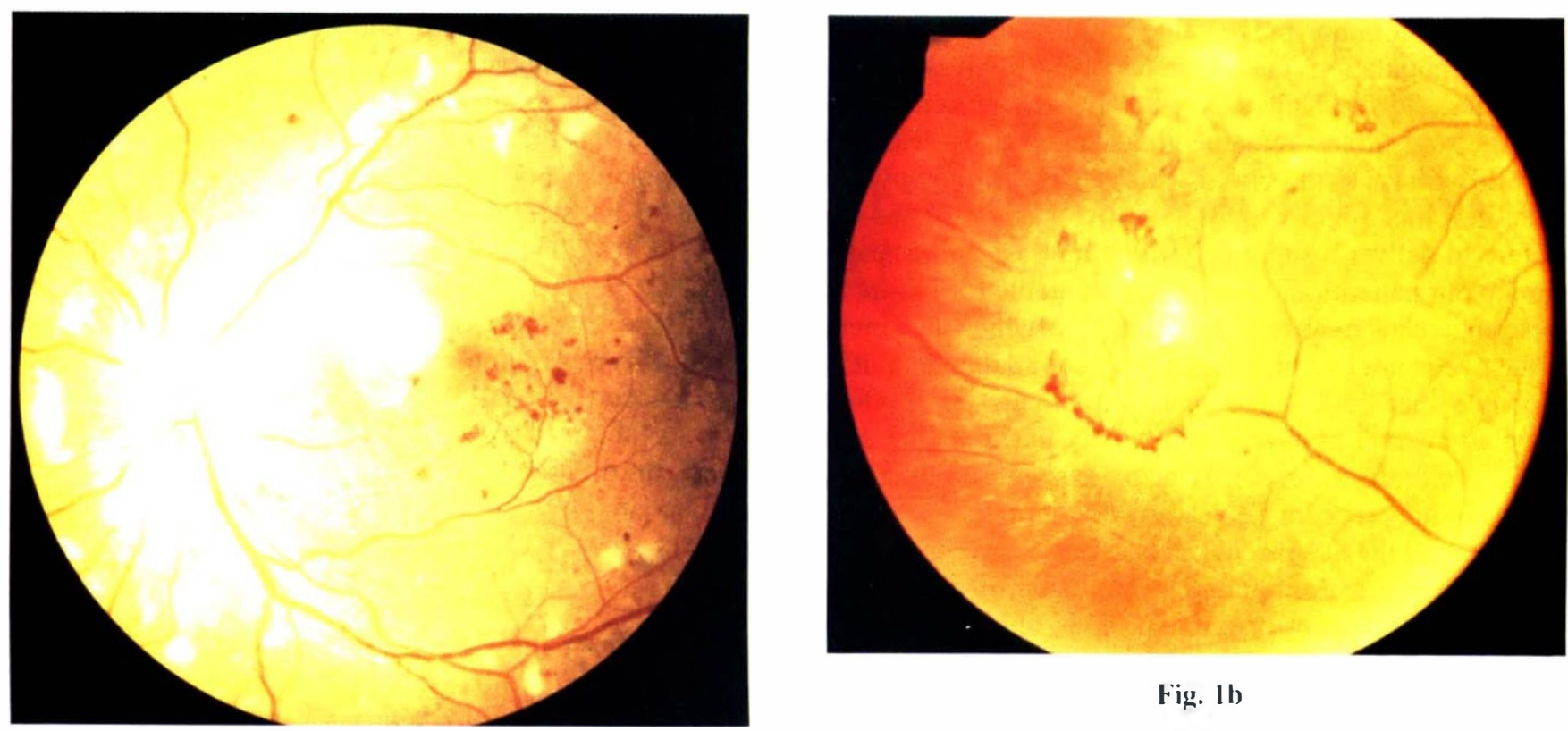

Fig. (1)

Fig. Ia

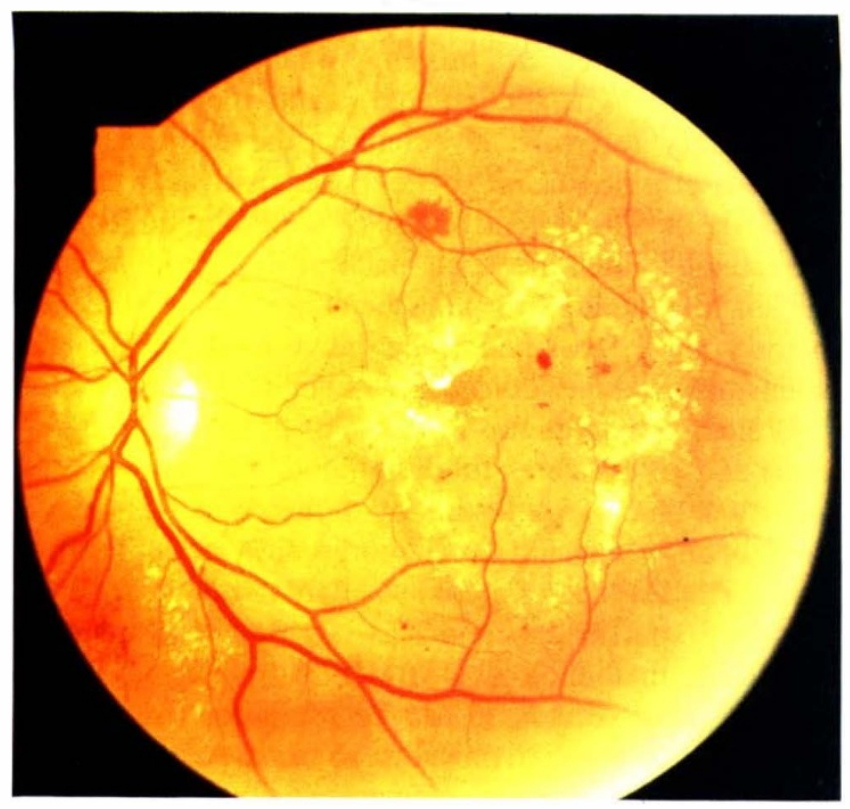

Fig. Ic

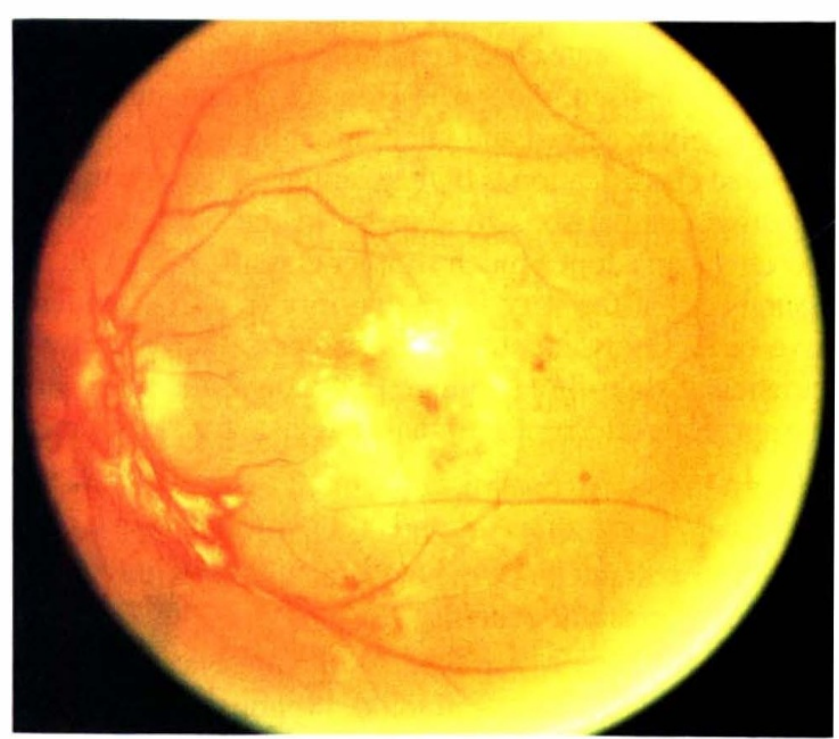

Fig. 1 d

Fig. 1. The sight-threatening diabetic retinopathies: (a) pre-proliferative, (b) proliferative (peripheral new vessels), (c) maculopathy with macular oedema, (d) combined lesions (maculopathy and disc new vessels).

\section{SCREENING OPTIONS: SPECIFICS}

Five screening options merit serious consideration. As will become evident, they are not mutually exclusive and almost certainly will be used in combination to address the problem. For any given country the deployment mix of screening methods will be determined by the organisation, resources and priorities of its national health care system.

Consultant ophthalmologists are justly regarded as the gold standard defined above. They are specialists in eye disease, will not fail to detect sight-threatening retinopathy, and of course are responsible for administering all necessary treatment. Unfortunately they are comparatively rare: in the United Kingdom there are about 400 consultant ophthalmologists, i.e. one consultant per
140000 population, with ultimate responsibility for the care of all eye diseases. It would be absurd to expect each member of this small group to devote valuable clinical time to the annual examination of perhaps 2000 diabetics, only 1 in 10 of whom has serious disease. Even if the exercise were practicable, the National Health Service is not so arranged as to permit open access or self-referral of a patient to a specialist. Similar reservations apply with equal force in all developed countries and are even more compelling in less developed health systems, where precious ophthalmological time is spread thinly over the other great common causes of blindness. In short, ophthalmologists will always act as final arbiters of secondary or tertiary referral in patients with identified disease, and will 
judge whether treatment is appropriate; but they have no part to play in the screening process per se. It is difficult to believe that this conclusion will ever be modified.

Diabetologists (physicians with particular interest in diabetes) would seem at first be to the obvious group to screen for retinopathy. Unlike ophthalmologists, their clinical responsibility is confined to diabetes care in all its aspects and they are well versed in the complications of a disease for which they profess special knowledge. Their performance as screeners has come under close scrutiny in the past decade and two serious reservations are apparent. Firstly, not all diabetic patients actually attend a specialist diabetic clinic: indeed clinic attenders are in a minority in the United Kingdom, where it is reliably estimated that less than $50 \%$ of all diabetics are known to and cared for by a hospital-based centre. ${ }^{17}$ Secondly, the accuracy of diabetologists in detecting retinopathy is disappointing: consultants detect only about one half of cases of serious eye disease and the proportion is even lower if the eye is examined by junior medical staff in the training grades. $^{18,19}$

Naturally it has been concluded that many internists are incapable of performing adequate retinal examination and the current recommendations of the American Diabetes Association for diabetic eye screening are based on this discouraging premise. ${ }^{20}$

Fortunately the situation is not so bleak as first appears and can be redressed successfully by a comparatively small outlay in time and training. In our own clinic the approach has been to recognise the serious nature of the problem, acknowledge clinical deficiencies and set about the remedy by arranging for formal training by ophthalmologists, in retinal examination, of all diabetic clinic staff with responsibility for eye examination. The two essentials of proper training are easy proficiency in the use of the direct ophthalmoscope and pattern recognition of the early signs of sight-threatening disease. The results of this approach were evaluated in 1981, in a series of 1000 patients examined serially by both ophthalmologists and physicians, and showed conclusively that trained diabetologists were as accurate as the eye specialists in the detection of retinopathy. ${ }^{15,21}$ Formal ophthalmological training was therefore adopted as standard in our diabetic service, and in the past decade has been refined further only by judicious use of fundus photography and the indirect ophthalmoscope when necessary. With the latter instrument, the retina can be adequately visualised in many patients with early lens opacities or hazy media and the need for ophthalmological referral is thereby obviated.

Thus there is no good reason why internists who specialise in diabetes should be unable to screen confidently for the most important and feared complication in their patients. The prerequisites are a willingness to acknowledge and rectify a common clinical deficiency; arrangement of clinic logistics so that examination of the eye is central to annual diabetic review and not a superficial afterthought; and the creation of good conditions (a suitable darkroom, accurate assessment of visual acuity, prior mydriasis with tropicamide, measurement of blood pressure) before the examination. All these requirements are simple and most of the practical aspects, short of ophthalmoscopy, are undertaken by specialist clinic nursing staff. Facilities to perform indirect ophthalmoscopy or retinal photography are useful but marginal luxuries. With this approach, about $25 \%$ of cases of retinopathy are over-referred for more detailed study by fluorescein angiography, but this false positive rate is economically acceptable and identical to the performance of ophthalmologists. ${ }^{7}$ It can reasonably be concluded that internists specialising in diabetes are capable of acting successfully as retinal screeners in the $50 \%$ (or less) of the diabetic population who attend their clinics: quite apart from the desire to do well by the patient, medicolegal considerations alone (litigation if retinopathy is missed) should encourage this approach.

Primary care physicians (general practitioners) carry the heavy responsibility of providing all clinical care for diabetic patients who never attend a hospital clinic.. Often this is not by medical choice: their lists include elderly diet-treated diabetics whose contact with the surgery is minimal, and young persons with long histories of type 1 diabetes, vulnerable to proliferative retinopathy but estranged from care and defaulters from hospital. Several small studies in recent years have examined the accuracy of general practitioners in screening for retinopathy. To acknowledge that their performance is extremely disappointing, with only 10-20\% of all sight-threatening lesions detected, is not to denigrate their broad clinical skills. Rather it is acceptance that a condition affecting perhaps $2 \%$ of the practice will never allow the doctor sufficient experience to diagnose retinopathy with confidence. In a group practice of 10000 patients, with half the diabetics attending a hospital clinic for annual review, only 2 patients per week on average will require ophthalmoscopy and this foundation is far too shaky for accurate diagnosis. Recent studies from Hammersmith Hospital, London, and Georgetown University of Washington, United States, indicate that the screening performance of general practitioners can be improved dramatically by quite short courses of instruction in direct opthalmoscopy, typical success rates rising from $16 \%$ to $38 \%$ after training. ${ }^{22,23}$ These studies are encouraging but do not address the fact that only a minority of primary care physicians are motivated to seek special training in a condition affecting so few of their patients, and also beg the questions as to how often retraining is necessary and how accuracy is audited.

In summary, it is highly probable that general practitioners will never provide more than a very small fraction of the screening service for retinopathy. Those who do assume the role will probably be designated diabetic specialists, in large group practices, who have undergone special training, are regularly audited and have created a suitable environment for accurate ophthalmoscopy.

Fundus photography is regularly invoked as an attractive screening option. In the past 10 years the ingenuity of 


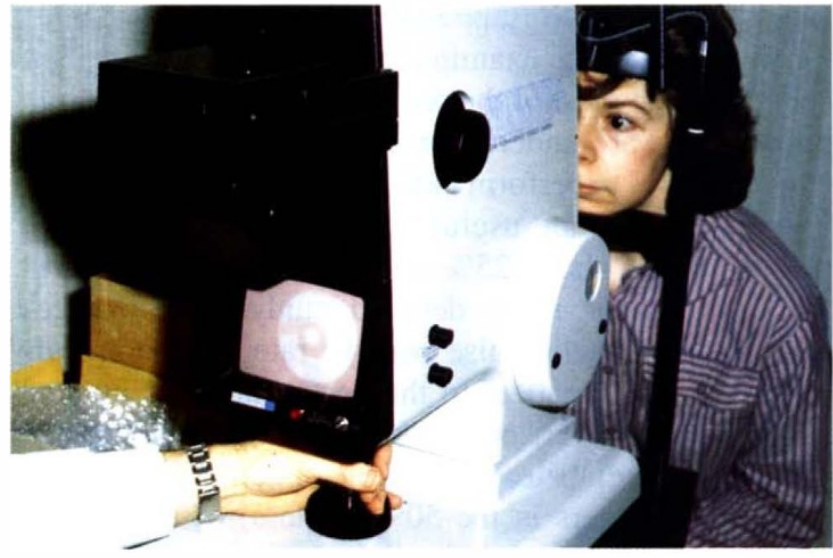

Fig. 2a

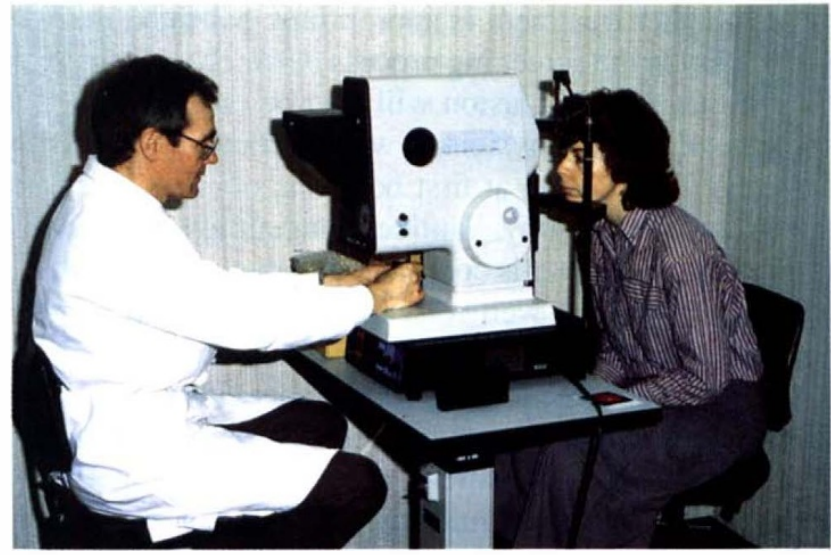

Fig. 2b

Fig. 2. (a) The non-mydriatic fundus camera. (b) The eye is visualised on a television screen.

the optical industry has devised the non-mydriatic fundus camera (Fig. 2) which is available from at least three Japanese manufacturers (Canon, Kowa and Topcon). In this instrument the operator visualises the retina on a TV screen by a beam of infrared light directed through the undilated pupil. The patient fixates on a point light source in the centre of the lens, which subtends an angle of about $45^{\circ}$. The photograph is taken by electronic ring flash and the field includes the optic disc, macula and temporal vascular arcades. Interchangeable film backs are available and photographs can be obtained as Polaroid prints (ISO 64) or $35 \mathrm{~mm}$ colour reversal or negative film, both the latter in ISO speeds 64-100. Obvious attractions include the facts that no prior patient preparation is necessary, provided that pupillary diameter exceeds $4 \mathrm{~mm}$, and that the instrument is (comparatively) portable, being capable of temporary installation in a health centre or any other suitable locus. The photographs can be read at leisure by an experienced interpreter.

These properties have excited speculation that the instrument would prove suitable for community-based use, being employed rather in the manner of mass miniature chest radiography of an earlier era and targeting the many diabetic patients who have no regular contact either with hospital or with their general practitioner. Originally its performance was carefully assessed by Klein's group in Wisconsin ${ }^{24}$ and latterly in the broader clinical area. Following several small hospital-based studies, two more substantial studies have been undertaken in the United Kingdom. The British Diabetic Association funded a study of non-mydriatic retinal photography in 2159 patients recruited from six diabetic clinics in the North of England to which a mobile camera was taken, and the results compared with the findings on direct ophthalmoscopy by internists with no special training. ${ }^{25}$ A more ambitious exercise was initiated by the Department of Health in a study which examined the eyes of 3318 patients by a variety of screening techniques including photography and ophthalmoscopy by general practitioners, optometrists or hospital diabetologists. ${ }^{26,27}$ In these studies the camera has been demonstrated to be as accurate as untrained hospital internists in detecting ret- inopathy, perhaps more so for maculopathy. Equally its overall performance is rather disappointing, with a failure to detect $33-60 \%$ of cases of serious retinopathy. Many of the problems are technical - photographs spoiled by lens opacities or hazy media, lesions outwith the lens' field of view, small and irregular pupils ${ }^{24.28}$ - but carry the clear inference that the non-mydriatic fundus camera cannot be recommended as sole option for a national screening programme. On the other hand, it may well have a role to play in examining elderly patients or young defaulters who cannot be reached by other methods. The photographs should always be made on colour reversal film (transparencies for projection) since the resolution of Polaroid film (20 lines/mm) is too poor for accurate interpretation.

Ophthalmic opticians (optometrists) are a large professional body, expert in detection of refractive errors and significantly superior to most internists in use of the direct ophthalmoscope. The bulk of the population in all developed countries has ready access to their facilities and uses them without prior medical referral. Sight testing is free for all diabetic patients in the United Kingdom and most persons respond to the visual physiology of ageing by purchasing reading glasses. Thus there are excellent reasons for believing that optometrists can play an important part in screening for retinopathy, and small but encouraging clinical studies have supported this belief. ${ }^{29.30}$ It is established that optometrists detect diabetic retinopathy with high sensitivity (which is essential) but low specificity (which can be improved by training). Much more work and larger studies are needed to define their precise involvement in the screening process but they are ideally placed to perform the task and many clinicians consider that with appropriate ophthalmic tuition-emphasising the need for mydriasis in all patients and defining the sightthreatening retinopathies - optometrists would be most valuable in screening the elderly persons who attend neither hospital nor general practice and are at particular risk from maculopathy.

\section{CONCLUSIONS}

This brief review has only touched the surface of an 
immensely important and fascinating subject and concludes with my personal view of how screening options should be deployed in the United Kingdom:

1. It is inappropriate to employ ophthalmologists as screeners.

2. Diabetologists should have primary responsibility for screening those patients who attend a hopsital clinic, either regularly or for annual review. They can discharge the task successfully only with proper ophthalmic tuition, which should be built into their specialist training.

3. General practitioners will play little part in retinopathy screening. For patients whose diabetic care is based exclusively in general practice, the labour of eye screening can be divided between a mobile camera unit, visiting the practice, and local optometrists.

4. Optometrists should be prepared to undertake screening of the (mainly elderly) patients who do not attend a hospital clinic, and can do so successfully with appropriate training. This initiative should be encouraged and made known to the public.

5. None of the above options will ensure eye screening for young defaulters with insulin-dependent diabetes, estranged or alienated from all medical care, whose only regular contact is for renewal of insulin prescriptions. This group presents late and yields an annual toll of preventable blindness from advanced proliferative retinopathy. Our clamant need is to warn them, by whatever means, of the visual risks incurred by failure to have a regular eye examination.

Key words: Diabetes, Retinopathy, Screening.

\section{REFERENCES}

1. Wilson JMG, Jungner G. The principles and practice of screening for disease. Public Health Papers 34. Geneva: WHO, 1968.

2. Harris MI, Klein R, Welborn TA, Khurman MW. Onset of NIDDM occurs at 4-7 years before clinical diagnosis. Diabetes Care 1992;15:815-9.

3. Von Jaeger E. Beiträge zur Pathologie des Auges, vol. 2, Lieferung. KK Wien, Hof- und Staatsdruckerei, 1855:33 (table XII).

4. The Diabetic Retinopathy Study Research Group. Photocoagulation treatment of proliferative diabetic retinopathy: the second report of diabetic retinopathy study findings. Ophthalmology 1978;85:82-106.

5. Sullivan PM, Caldwell G, Alexander N, Kohner EM. Longterm outcome after photocoagulation for proliferative diabetic retinopathy. Diabetic Med 1990;7:788-94.

6. Davies EG, Petty RG, Kohner EM. Long term effectiveness of photocoagulation for diabetic maculopathy. Eye 1989;3: 764-7.

7. Foulds WS, MacCuish AC, Barrie T, et al. Diabetic retinopathy in the West of Scotland: its detection and prevalence, and the cost-effectiveness of a proposed screening programme. Health Bull (Edinb) 1983;41:318-26.

8. Javitt JC, Canner JK, Sommer A. Cost effectiveness of current approaches to the control of retinopathy in type 1 diabetics. Ophthalmology 1989;96:255-64.
9. Skyler J. Living with complications of diabetes. In: Hamburg $\mathrm{J}$, editor. Behavioural and psychosocial issues in diabetes: proceedings of a national conference. New York: Harper and Row, 1979.

10. Auer J. Quality of life of diabetics on renal replacement therapy: special problems need special solutions. Proc Eur Dial Transplant Nurse Assoc 1984;13:96-9.

11. Porta M, Kohner EM. Screening for diabetic retinopathy in Europe. Diabetic Med 1991;8:197-8.

12. Witkin SR, Klein R. Ophthalmologic care for persons with diabetes mellitus. JAMA 1984;251:2534-7.

13. WHO/IDF Europe. Diabetes care and research in Europe: the Saint Vincent Declaration. Diabetic Med 1990;7:360.

14. Foulds WS, MacCuish AC, Barrie T, et al. The cost-effectiveness of screening for diabetic eye disease. Semin Ophthalmol 1987;2:45-50.

15. Scobie IN, MacCuish AC, Barrie T, et al. Serious retinopathy in a diabetic clinic: prevalence and therapeutic implications. Lancet 1981;2:520-1.

16. Doucet J, Retout A, Poutrain JR, et al. A multi-factorial etiological approach to diabetic dyschromatopsia: study of 100 diabetics. Diabete Metab 1991;17:31-7.

17. Yudkin JS, Boucher BJ, Schopflin KE, et al. The quality of diabetic care in a London healthcare district. J Epidemiol Community Health 1980;34:277-80.

18. Sussman ES, Tsioras WG, Soper KA. Diagnosis of diabetic eye disease. JAMA 1982;247:3231-4.

19. Ryder REJ, Young S, Vora JP, et al. Screening for diabetic retinopathy using polaroid retinal photography through undilated pupils. Practical Diabetes 1985;2(5):34-9.

20. American Diabetes Association. Position statement: eye care guidelines for patients with diabetes mellitus. Diabetes Care 1988;11:745-6.

21. Barrie T. Should physicians or ophthalmologists screen diabetics for retinopathy? Diabetologia 1981;18:665.

22. Patel V, Rassam SMB, Kohner EM. Screening for diabetic retinopathy in general practice: feasibility and limitations. Diabetic Med 1992;9:117a.

23. Awh CC, Cupples HP, Javit JC. Improved detection and referral of patients with diabetic retinopathy by primary care physicians: effectiveness of education. Arch Intern Med 1991;151:1405-8.

24. Klein R, Klein BEK, Neider MW, et al. Diabetic retinopathy as detected using ophthalmoscopy, a non-mydriatic camera and a standard fundus camera. Ophthalmology 1985;92: 485-91.

25. Taylor R, Lovelock L, Tunbridge WMG, et al. Comparison of non-mydriatic retinal photography with ophthalmoscopy in 2159 patients: mobile retina camera study. BMJ 1990; 310:1243-7.

26. Buxton MJ, Sculpher MJ, Ferguson BA, et al. Screening for treatable diabetic retinopathy: a comparison of different methods. Diabetic Med 1991;8:371-7.

27. Sculpher MJ, Buxton MJ, Ferguson BA, et al. A relative cost-effective analysis of different methods of screening for diabetic retinopathy. Diabetic Med 1991;8:644-50.

28. Barrie T, MacCuish AC. Assessment of non-mydriatic fundus photography in detection of diabetic retinopathy. BMJ 1986;293:1304.

29. Burns-Cox CJ, Dean Hart JC. Screening of diabetics for retinopathy by ophthalmic opticians. BMJ 1985;290:1052-4.

30. Hill RD. Screening for diabetic retinopathy at primary care level. Diabetologia 1981;20:9. 